In memoriam

\title{
Fulvia Rosemberg: memórias a partir do lugar do afeto
}

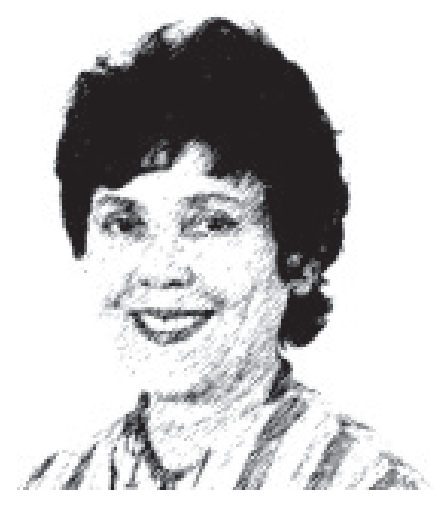

A vida e a morte são

O sorriso lisonjeiro

E o amor tem o navio

E O navio o marinheiro

A Vida e a Morte (por Florbela Espanca, aos 8 anos de idade)

Quando recebemos o convite para escrever este texto, fomos pegos de surpresa e precisamos de algumas horas para confirmar. A surpresa se deu em dois sentidos: merecimento e capacidade. Primeiro, não estávamos seguros se merecíamos mesmo tal presente, pois tanto Fúlvia Rosemberg como a Revista Estudos Feministas são, para nós e para muitos/as, referências de conhecimento e cultura e, portanto, escrever este texto não era tarefa para qualquer um. Segundo, tínhamos dúvidas se seríamos capazes de desenvolver tal tarefa. Neste caso, a dúvida era tanto em função da dor da perda (que se potencializa, à medida que as memórias são acionadas ao elaborarmos um texto desta natureza), como também pelo reconhecimento do nosso limitado conhecimento sobre a grande obra de Fúlvia. Enfim, nossa primeira reação foi: há pessoas muito mais capazes e legítimas de tal honraria.

Continuamos com essa certeza, mas, conversando com uma amiga muito especial que nos foi apresentada pelo feminismo (Márcia Laranjeira), decidimos aceitar o convite, pensando que esta não será nem a única, nem a melhor homenagem a nossa Fúlvia. "Vocês podem escrever um texto a partir do lugar em que vocês se sentem mais à vontade!", nos disse Márcia. Assim, aceitamos este convite e resolvemos escrevê-lo a partir do lugar das boas recordações e do profundo afeto que nutrimos por Fúlvia. ${ }^{1}$

Precisamos começar dizendo que foram inúmeras as contribuições de Fúlvia para nossas vidas, para o movimento feminista, para o campo de defesa dos direitos da criança,

Copyright ( 2014 by Revista Estudos Feministas.

${ }^{1}$ A chegada de um carinhoso e-mail enviado por Júlia, filha de Fúlvia, foi também decisivo para aceitarmos essa incumbência e fazê-la de modo tão especial. 
para as políticas de promoção da igualdade racial e para o campo da docência e dos estudos e pesquisas em psicologia social. Fúlvia foi uma das grandes defensoras de uma educação infantil de qualidade e do direito à creche; desenvolveu e orientou uma série de pesquisas sobre gênero, raça e idade; dedicou-se a pesquisar oportunidades educacionais brasileiras da ótica de gênero e raça; coordenou a sessão brasileira do Programa Internacional de Bolsas de Pós-Graduação da Fundação Ford, que assumiu, no Brasil, a configuração de um programa de Ação Afirmativa (AA) para negros e indígenas, entre outros segmentos sociais. Ela não apenas fez, como ensinou e apoiou outros fazeres. Por isso, nosso texto jamais conseguiria resumir, sem o pecado da simplificação, uma obra tão extensa e tão significativa.

Assim, optamos por produzir um texto situado, narrando episódios a partir dos quais sinalizaremos algumas de suas contribuições para nossas vidas e para a vida de muitos/as outros/as. Possivelmente, muitos/as recordarão de situações semelhantes e outros/as poderão acrescentar informações mais precisas. Esperamos que nosso exercício, parcial e passional, possa inspirar, portanto, outras produções, mantendo viva a memória de nossa amiga e perpetuando sua obra.

Nosso primeiro contato com Fúlvia foi há 20 anos, em 1994, quando a procuramos para obter informações sobre o processo seletivo para o Programa de Pós-Graduação em Psicologia Social da PUCSP, onde lecionavam ela e a Profa. Mary Jane Spink, que vieram depois a ser nossas orientadoras.

Fúlvia havia sido indicada por duas professoras muito especiais em nossa graduação: Silke Weber e Aida Novelino. Silke a havia conhecido na França, no especial ano de 1968, quando ambas estudavam e viviam o feminismo em suas densas, tensas e profícuas manifestações, fora e dentro da academia europeia. Aida, por sua vez, havia conhecido Fúlvia quando esta já havia regressado a São Paulo. Ela nos falou com entusiasmo sobre uma das mais importantes contribuições de Fúlvia para o movimento feminista brasileiro, na década de 1980: o Mulherio.

O Mulherio foi uma das primeiras publicações feministas brasileiras. Esta publicação bimestral durou de 1981 a 1988 e tinha como foco "a condição feminina no Brasil", e como público: os/as profissionais de comunicação, os grupos de mulheres e as entidades culturais e acadêmicas. ${ }^{2}$ Em seu Número 0 (março-abril de 1981), traziam-se os objetivos da publicação e uma explicação sobre a escolha do nome:

\begin{abstract}
Mulherio. Quase sempre, a palavra empregada com sentido pejorativo, associada a histerismo, gritaria, chatice, fofocagem ou, então, "gostosura". Mas qual é a palavra relacionada à "mulher" que não tem essa conotação? O próprio verbete "mulher" é apresentado no dicionário de forma especial. Segundo o consagrado Aurélio Buarque de Holanda, mulher é: "1. Pessoa do sexo feminino, após a puberdade; 2. esposa". Em seguida a definição, vêm as posições usualmente feitas com a palavra: "à toa" "da comédia", "da rua", "da vida", "da zona", "da rótula", "do fado", "errada", "perdida" etc. - todas sinônimo de meretriz. As três exceções são: "mulher de César" (de reputação inatacável), "mulher do piolho" (muito teimosa) e a cinematográfica "mulher fatal". Consulte no mesmo dicionário as composições feitas com o verbete "homem": "de ação", "de bem", "de Estado", "de letras", "de negócios" etc.
\end{abstract}

\footnotetext{
${ }^{2}$ O Mulherio tinha como editoras Fúlvia e Adélia Borges. O conselho editorial (informado na edição 0) era composto por: Carmem Barroso, Carmem da Silva, Cristina Bruschini, Elizabeth Souza Lobo, Eva Alterman Blay, Fúlvia Rosemberg, Heleieth Saffioti, Lélia Gonzales, Maria Carneiro da Cunha, Maria Moraes, Maria Malta Campos, Maria Rita Kehl, Maria Valéria Junho Penha, Marília de Andrade, Marisa Correa e Ruth Cardoso. O projeto gráfico era de Derly Barroso, e a jornalista responsável, Adélia Borges. O acervo deste periódico está completamente disponível no site da FCC (www.fcc.org.br/conteudosespeciais/mulherio).
} 
Mulherio, por sua vez, nada mais é do que "as mulheres" ou "uma grande porção de mulheres". É o que somos, é o que este jornal será. Sim, nós vamos nos assumir como - Mulherio e, em conjunto, pretendemos recuperar a dignidade, a beleza e a força que significam as mulheres reunidas para expor e debater seus problemas. De uma maneira séria e consequente, mas não mal-humorada, sizuda ou dogmática.

Num depoimento publicado pela Fundação Carlos Chagas, ${ }^{3}$ Fúlvia expressa sua paixão por aquele projeto e pelos efeitos que o Mulherio produziu:

\begin{abstract}
Mulherio! O nome veio da Carmen da Silva, recuperar palavra desairosa sobre nós mulheres. Dar uma piscadela para a irreverência, enquanto imprensa nanica, mas guardando a seriedade de um projeto da Fundaçáo Carlos Chagas. Muita ousadia daquele grupo de pesquisadoras e de jornalistas, produzir um jornal feminista, independente, com recursos escassos, menos nossa vontade de fazê-lo, pontualmente, mantendo, se não a irreverência, pelo menos um bom humor. Adélia Borges e Inês Castilho, corajosas ao embarcarem na experiência, davam o tom. Marlene Rodrigues, diagramadora, compunha o visual. Miriam Tanus mantinha o cotidiano.
\end{abstract}

As reuniões de pauta eram fantásticas, com sugestões muito avançadas para a imprensa militante mas que nem sempre puderam se concretizar.

A adesão de ativistas e acadêmicas foi imediata e calorosa, colaborando com artigos e comentários. Algumas matérias são inesquecíveis e me voltam à memória, como aquela sobre a velhice com sua dançarina viúva diante do espelho. Saudades do mulherio!

Ler este depoimento reacende a saudade de Fúlvia e da forma sempre "hiperlativa" e sedutora com que ela falava sobre seus projetos, suas opiniões e seus desejos.

Mas, voltando ao nosso primeiro encontro com Fúlvia, quase uma década depois do encerramento do Mulherio... é preciso reconhecer que não foi agradável. Ela nos recebeu com poucas e assertivas palavras, que nos foram sentidas, naquele momento, como rudes. Nos disse que as informações sobre o processo seletivo para o curso de mestrado eram públicas e que não poderíamos participar naquele dia do seu grupo de pesquisa (Núcleo de Estudos sobre Gênero, Raça e Idade - NEGRI), porque do grupo só participavam estudantes regularmente matriculados/as no curso.

A forma direta e o discurso orientado pela justiça e pela equidade foi uma marca desta e de todas as outras inúmeras conversas que tivemos com Fúlvia. Mas ainda não a conhecíamos. Não sabíamos que, no caso de Fúlvia, deveríamos sempre evitar as impressões fáceis. De fato, ela não era uma "pessoa fácil". Como dissemos em outro texto, esse talvez fosse seu maior encanto. Ela não se oferecia gratuitamente. Precisava ser conquistada. Ela também jamais pedia algo, precisava conquistar, fazia por merecer. Viveu intensamente como se, de algum modo, pressentisse que seria uma vida curta, mas de intensas marcas.

No entanto, ela também não nos conhecia e não sabia de algo importante: havíamos viajado de Recife a São Paulo tão somente para dialogar com docentes dos cursos de Pósgraduação em que interessávamos ingressar; ou seja, saímos de sua sala mobilizados e com uma primeira impressão nada agradável. Apesar disso, decidimos participar do processo seletivo e fomos aprovados.

Ingressamos no curso de Mestrado em Psicologia Social da PUCSP, em 1995, e já na primeira aula Fúlvia mostrou-se atenta e disponível para conversar conosco sobre nossos projetos e já nos convidou para participar do seu Núcleo de Pesquisa. ${ }^{4}$

${ }^{3}$ http://www.fcc.org.br/conteudosespeciais/mulherio/depoimentofluvia.html

${ }^{4}$ Jorge foi seu orientando; Benedito, seu aluno. 
Algum tempo depois, Fúlvia nos surpreendeu quando, de modo bem sutil, escalou-se para ir conosco ao "Segundo ato", barzinho que ficava ao lado da PUC, onde íamos com outros colegas do curso celebrar a vida e falar das agruras de viver e de estudar em São Paulo. ${ }^{5}$ Naquela ocasião, pudemos conversar sobre o primeiro encontro e brindamos uma amizade que alimentou vários outros encontros, sempre marcados pelo bom humor, por vezes ingênuo, por vezes mais ácido, pelo carinho de um bom abraço, pela transparência de posições e pela escuta e disputa de argumentos.

Foi Fúlvia quem nos apresentou as leituras, as pessoas e as instituições de maior referência no feminismo brasileiro e internacional. Foi ela quem nos falou, com vigor, que ciência, arte e política são campos com regras e processos particulares, mas que dialogam e se afetam mutuamente. Foi ela quem nos apresentou Johannes Vermeer, um pintor holandês que teve uma vida curta (1632-1675) e uma produção pequena, mas de beleza rara e estilo, cor e luz inconfundíveis.

Foi ela quem nos apresentou a Fundação Carlos Chagas, onde encontramos os textos que nos ajudaram a definir, na época, nossos objetos de pesquisa. Também nos apresentou a organização Não Governamental ECOS - Comunicação em Sexualidade, na época coordenada por uma de suas ex-orientandas (Silvia Cavasin). Nas ECOS, conhecemos pesquisadores/as que tinham o prazer do encontro e o desejo de produzir uma ciência comprometida com a transformação social, entre eles/as alguns/mas que têm por Fúlvia muito carinho e gratidão, tais como: Margareth Arilha, Leandro Andrade, Elizabete Franco (que foram seus orientandos) e Sandra Unbehaum.

Foi Fúlvia também quem nos incentivou a fundar o Instituto PAPAl e o Gema/UFPE e a seguir no desenvolvimento de pesquisa e outras intervenções políticas sobre homens e masculinidades, a partir da perspectiva feminista de gênero.

Na verdade, foi ela quem idealizou o PAPAl, incentivando-nos a apresentar nosso primeiro projeto ao edital da MacArthur, quando finalizávamos nossas dissertações (em 1997). Apresentamos um esboço muito capenga e ela, depois de um café e um cigarro, voltou com "gosto de gás" (como se diz por aqui) e embarcou conosco na viagem.

Ela elaborou conosco o projeto e desenhou as principais linhas de ação, que envolviam ensino, pesquisa e extensão, já no seu primeiro esboço. Nos indicou pessoas de contato. Nos ajudou a escolher o nome da instituição e a pensar a ideia do boneco gigante de Olinda como dispositivo cultural que poderia promover a visibilidade de cenas de cuidado promovidas por homens. Até a viagem feita de São Paulo a Recife para articular parcerias foi paga com as milhas dela.

Foi ela quem nos ajudou a definir o "cuidado" como princípio ético norteador das ações com/sobre homens a partir da perspectiva feminista de gênero, dando visibilidade à ideia de que, em nossa cultura, o cuidado é tanto desvalorizado como radicalmente atribuído às mulheres, menos como direito e mais como obrigação, ao passo que os homens são alijados e muitas vezes se alienam da possibilidade dessa experiência.

Quem teve o prazer de ler as produções de Fúlvia e conviver com ela, há de concordar conosco que Fúlvia era, na mesma medida, exigente e cuidadosa. Apaixonada e apaixonante. Gostava de quem tinha paixão pela vida, como ela.

Fúlvia foi $100 \%$ educadora. Alguns episódios nos fazem recordar sua disponibilidade em aprender e ensinar, questionando certezas e provocando reflexões e deslocamentos, seja em sala de aula, quando nos provocava e nos exigia a definição de um objeto e uma pergunta de pesquisa inteligível, seja em momentos mais informais, como o dia em que ela

${ }^{5}$ Vera Menegon, Luiz Rala, Érico Renteria (e Esperanza, sua companheira), Vania Neri, Elaine Laviola, Leandro Feitosa e tantos outros/as amigos/as compartilharam destes agradáveis encontros e difíceis momentos. 
nos relatou sobre a decisão de manter o sobrenome do seu ex-marido (com quem ela sempre manteve respeitosa e carinhosa relação, mesmo após a separação). Como ela costumava dizer: "Fúlvia Rosemberg foi criada por mim. Não pelo meu casamento". Muito simplista essa ideia de que retirar o sobrenome do marido seria uma forma de contrapor-se à ordem patriarcal. Há muitas formas mais efetivas de fazê-lo. E pode ter certeza que Fúlvia o fez.

Lembramos também o dia em que nos revelou que era irmã do polêmico (termo que diz muito pouco sobre) Luiz Mott, numa mesa de bar, em que alguém enunciava uma crítica a ele. Poderia ter ficado calada, ouvir tudo e só depois se manifestar, mas, de modo ético, preferiu adiantar a informação de modo a não gerar constrangimento e, de algum modo, colocar todos na mesma condição de pessoas informadas.

Mais recentemente, quando ela esteve em nossa casa, em Recife, preparamos um prato especial, daqueles que se pensa com bastante antecedência e que tarda uns dois dias para preparar. Após algumas taças de vinho, risadas e atualização de informações, ao sentar à mesa ela nos faz uma pergunta intrigante: "Vocês são meus amigos?" Mesmo sem entender o motivo da pergunta, respondemos prontamente que sim. Essa foi a forma delicada (que poucos são capazes) de nos dizer que entre amigos não deve haver constrangimentos. Foi a forma carinhosa de ela dizer que não gostava de bacalhau.

Memórias e momentos de aprendizagem são tantos e tão intensos quanto a saudade. Por isso, ao encerrar este texto, surge uma terceira resistência que não se mostrou tão evidente quando recebemos o convite para produzi-lo, mas que agora dói quando materializamos uma certeza: não mais nos encontraríamos com ela no final de setembro de 2014, como havíamos planejado e desejado. Não poderemos mais convidá-la para fazer o prefácio de um livro sobre memórias que estamos concluindo. Não poderemos mais abraçá-la, "tirar onda" com ela, discutir com ela, aprender com ela, senti-la... Nem poderemos mais comer o carneiro com cuscuz marroquino servido na bela tajine, acompanhado de um delicioso vinho tinto, que ela nos ofertava em seu apartamento com tanto carinho; não poderemos mais pedir-lhe cópia do conto erótico que ela escreveu e com o qual ganhou um concurso, no qual teve que usar, na época, um pseudônimo; não poderemos mais ofertar-lhe uma simples gérbera. ${ }^{6}$

Assim, assumindo a incapacidade de escrever aqui as "últimas palavras", agradecemos a Carmem Barroso, que, com sua manifestação de afeto, ajudou-nos a encontrar as belas palavras com as quais gostaríamos de finalizar essa especial homenagem da Revista Estudos Feministas à grande mulher, Fúlvia Rosemberg, pois, como diz a poetisa feminista portuguesa Florbela Espanca (que inspirou a epígrafe deste texto e que foi retratada num filme que nos acalentou no dia seguinte à partida de nossa amiga): "Há uma Primavera em cada vida. É preciso cantá-la assim florida".

Irmã ausente na visita à casa paterna (por Carmem Barroso)

Volta à Carlos Chagas após longos anos.

Pedaço de mim, pedaço de vida, grandes momentos revisitados.

Revendo meu nascimento profissional: colegas, amigas - na verdade irmás.

Também meu desabrochar na cidadania: companheiras.

Várias ausências. Onde esta Fúlvia?

\footnotetext{
${ }^{6}$ Compartilhamos com Gabriela Calazans um desses memoráveis momentos em que esta flor fez um sentido especial para nós.
} 
O choque: não está bem.

O olhar angustiado de quem conta revela o eufemismo:

Não é um mal passageiro.

No outro lado do celular, a voz tranquila de sempre:

Estou internada, fazendo testes de câncer.

Não queria saber o resultado dos testes do cérebro

mas eles foram bons.

Se declara um tanto cansada com as drogas tomadas para os testes,

Mas é a mulher de sempre

Firme e forte,

tendo clareza sobre o que quer e controle sobre o que faz.

Agora, deixa um buraco no mundo. Imenso.

Mas também deixa uma rica herança.

Seu exemplo e as inúmeras pessoas

Cujas vidas ela tocou.

Campeã das creches como justiça social e liberação feminina

Alma do Mulherio, abrindo novas fronteiras, fazendo ouvir novas vozes Ousada pesquisadora das injustiças raciais

Dinâmica impulsionadora de oportunidades para os injustiçados

Professora e mentora por excelência.

Muitos e muitas não a esquecerão

Muitas e muitos mudaram suas vidas por sua causa

Guardarei comigo recordações preciosas.

O primeiro dia em que nos encontramos.

A jovem que voltava de Paris com um vivo interesse nos estereótipos sexuais nos livros infantis.

Nossa afinidade imediata com uma causa comum.

A seriedade ao considerar nosso convite para se juntar à Carlos Chagas.

O trabalho da bibliografia anotada.

O senso de humor ao lidar com os egos

O rigor na metodologia

A disciplina na execução.

A ida a Brasília para inaugurar a CPI da Mulher

O deslumbramento de encontrar Nelson Carneiro nos esperando no aeroporto

O quarto compartido no Hotel Nacional onde dividimos ansiedades e

esperanças

A enorme responsabilidade enfrentada com competência e segurança.

Nossos caminhos se separaram,

mas nos encontramos várias vezes

Em diversos pedaços do mundo

Onde compartilhamos interesses comuns

Paixão pela mudança social, e claro

Mas também: boa comida

Boa literatura, boa vida.

Sofro sua ausência

Mas prezo muito

A presença da sua memória.

910 Estudos Feministas, Florianópolis, 22(3): 905-911, setembro-dezembro/2014 


\section{Produção}

Para quem quiser acessar uma lista das produções acadêmicas de Fúlvia Rosemberg, recomendamos uma visita ao seu currículo Lattes: Fúlvia Maria de Barros Mott Rosemberg, atualizado pela última vez a um pouco mais de um mês (em 14/08/2014).

Neste currículo, ela se apresenta da seguinte forma:

Possui graduação em Psicologia pela Universidade de São Paulo (1965) e doutorado em Psychobiologie de l'Enfant - Ecole Pratique des Hautes Etudes /Université de Paris (1969). Atualmente é pesquisadora consultora da Fundação Carlos Chagas, professora titular da Pontifícia Universidade Católica de São Paulo, onde coordena o Negri (Núcleo de Estudos de gênero, raça e idade). Tem experiência na área de Psicologia, com ênfase em Psicologia Social e Estudos Sociais da Infância, atuando, principalmente, nos seguintes temas: relações raciais, relações de gênero, relações de idade, ação afirmativa, educação e educação infantil.

Pretendemos, em breve, compilar textos e vídeos em que Fúlvia defende argumentos e apresenta reflexões éticas, políticas e conceituais sobre feminismo, sobre defesa dos direitos das crianças e sobre igualdade racial. Esse material será disponibilizado no site www.genero.org.br

Jorge Lyra

Universidade Federal de Pernambuco

Benedito Medrado

Universidade Federal de Pernambuco 